\title{
Vacinação: uma tematização que a imprensa privilegia
}

\author{
Vaccination: a key theme in the press
}

\section{Gomes, Sofia}

Universidade do Minho

sofiagomes11@hotmail.com

Lopes, Felisbela

Universidade do Minho

felisbela@ics.uminho.pt

Forma de citar este artículo:

Gomes, S. y Lopes, F. (2019). "Vacinação: uma tematização que a imprensa privilegia”, RAEIC, Revista de la Asociación Española de Investigación de la Comunicación, vol. 6, núm. 12, 259-288.

\section{Resumo:}

Os jornais generalistas portugueses interessam-se pouco pela prevenção da saúde, mas, quando falam disso, a prioridade centra-se na vacinação. Este é o tópico mais presente no noticiário da imprensa. Queremos aqui saber de que modo o assunto é agendado e quais as fontes mais privilegiadas para dele falarem. Para desenvolver este estudo, trabalhamos com uma amostra de 439 artigos que tiveram a prevenção como tema de noticiabilidade e que foram publicados entre 2012 e 2014 nos jornais Público, Jornal de Notícias, Diário de Notícias, Correio da Manhã, Expresso e Sol. Desses 439 artigos, foram selecionados 136 textos que centraram a sua tematização na vacinação. O estudo desenvolvido enquadra-se no projeto de doutoramento "Comunicação e Saúde: Jornalismo preventivo e fontes de informação" (SFRH/BD/89792/2012), financiado pela 
Fundação para a Ciência e Tecnologia, a decorrer no Centro de Estudos de Comunicação e Sociedade, na Universidade do Minho.

Palavras-chave: vacinação; jornalismo da saúde, agenda-building, fontes de informação

\section{Abstract:}

General portuguese newspapers are little interested in health prevention but when they talk about it the priority is given to vaccination. This is the most current topic on the news. Here we want to know how the subject is scheduled and who are the most privileged sources to speak about it.

In order to develop this study we worked with a sample of 439 articles that had the prevention as a news item and that were published between 2012 and 2014 in the newspapers Público, Jornal de Notícias, Diário de Notícias, Correio da Manhã, Expresso and Sol. From these 439 articles we selected 136 texts that focused on vaccination. This study is part of the PhD project "Communication and Health: Preventive Journalism and Information Sources" (SFRH/BD/89792/2012), funded by the Portuguese Foundation for Science and Technology, course at Communication and Society Research Centre at the University of Minho.

Keywords: vaccination; health journalism, agenda-building, sources of information.

\section{INTRODUÇÃO}

Em Portugal, a vacinação tem sido uma das prioridades dos sucessivos Ministérios da Saúde. Prova disso é a existência de um Plano Nacional de Vacinação (PNV), que entrou em vigor já em 1965, onde se apontam as idades para a toma de determinadas vacinas, funcionando o documento como uma espécie de guia que convém adotar a bem da saúde pública. Para que isso aconteça, impõe-se que os cidadãos estejam informados e, a esse nível, os média terão um papel importante devido à sua capacidade para disseminar informação para públicos de massa.

Tendo uma enorme centralidade entre os atores que gerem e aplicam a saúde, a vacinação é, antes de mais, um tema intrínseco às políticas de saúde que os média, 
particularmente a imprensa, privilegiam. Um despacho do Ministério da Saúde, datado de setembro de 2014, afirma que "compete à Direção-Geral da Saúde promover a adaptação dos mecanismos existentes de gestão do PNV ao novo esquema de vacinação", sendo essas vacinas facultadas à população de modo gratuito. A importância atribuída ao Plano de Vacinação num contexto político é bem visível no agendamento de notícias sobre saúde ao longo dos últimos anos. Inúmeros são os artigos publicados sobre vacinação nos jornais portugueses, identificando-se possíveis agendamentos implícitos por parte de fontes organizadas, nomeadamente ligadas a instituições governamentais. É isso que procuraremos explicar neste estudo.

\section{ENQUADRAMENTO TEÓRICO}

Considerando a saúde dos cidadãos um ponto de grande interesse público, torna-se imprescindível perceber como é feita a cobertura jornalística da prevenção na temática mais proeminente: a vacinação. Antes de nos abeirarmos da mediatização que é feita na imprensa generalista portuguesa, convém refletir acerca do modo como as fontes se organizam em torno de um agendamento mediático que se vai construindo no espaço público mediático.

\subsection{O PODER DAS FONTES INTERESSADAS}

As fontes são um dos actantes mais decisivos na construção da agenda mediática (Berkowitz, 1987). Sem elas, não há informação jornalística. Por isso, a relação entre jornalistas e fontes de informação nem sempre é fácil. O caso do jornalismo em saúde exige uma atenção especial devido a estarmos perante dois campos muito distintos. Esta complexa relação estimula uma maior proximidade entre o jornalista e as suas fontes, sendo que o jornalismo deve ter sempre presente que a sua qualidade é, em grande parte, tributária da fiabilidade das fontes e da qualidade da informação que elas transmitem (Gutiérrez e Jiménez, 2001; Muñoz-Torres, 1997).

No campo particular da saúde, apresentar uma informação equilibrada é um propósito que exige maior empenho do jornalista (Hodgetts et al., 2008). Aos jornalistas pede-se, então, que saibam traduzir as informações facultadas pelas fontes especializadas em 
saúde, que nem sempre sabem descodificar em linguagem comum aquilo que fazem (Corbett e Mori, 1999; Friedman, Tanner e Rose, 2014; Hinnant e Len-Rios, 2009). É também fundamental que os profissionais de saúde estejam conscientes da sua função de geradores de informação sobre saúde. Torna-se, então, indispensável aceder a fontes no campo da saúde que estejam dispostas a falar com os jornalistas (Gomes, 2012; Hodgetts et al., 2008). Esta é outra dificuldade: "descobrir fontes dispostas a falar com os media afigura-se uma tarefa árdua" (Gomes, 2012, p. 28).

Perante isto, sobressaem, sobretudo, as fontes oficiais e as organizações prestadoras de saúde, ou seja, fontes organizadas que procuram ativamente agendar o que fazem no espaço público mediático. Esta "forte dependência das fontes especializadas institucionais imprime uma dada forma às informações sobre saúde tratadas pelos média" (Lopes et al., 2012, p. 133), influenciando ainda o modo como estas são recebidas pelos públicos e as atitudes que estes tomam posteriormente. Por seu turno, estas fontes, ditas organizadas, podem também facilitar o trabalho do jornalista, quando Ihes facultam uma informação clara e concisa. Como sublinham Araújo e Lopes, "o processo de construção da notícia é o resultado de uma negociação entre jornalistas e fontes de informação, sendo que é um compromisso entre ambas as partes que marca a agenda mediática" (2014, p. 751).

\subsection{AGENDA MEDIÁTICA: QUE CONSTRUÇÃO?}

Sabemos que os média participam na construção social da realidade, na medida em que orientam a atenção da audiência em direção a determinados factos e/ou lógicas de pensamento dominante (Silveira e Marôpo, 2014). Fazem-no através do agendamento de temáticas e de pessoas e, com isso, interferem nos quadros de perceção que cada um de nós vai criando sobre a realidade. É, por isso, fundamental conhecer que agendamento é esse e, antes de mais, entender alguns quadros teóricos que nos auxiliam a enquadrar esta problemática. As teorias do agenda-setting e do agendabuilding ajudam-nos aqui a devolver algum pensamento crítico.

Sendo um ponto de referência para compreender a capacidade que os meios de comunicação têm para agendar as temáticas que devem fazer parte da preocupação dos 
leitores, a teoria do agenda-setting sustenta que os média dizem ao público sobre o que devem pensar e não o que pensar. Defendida por autores como Lippmann (1922) ou Cohen (1963), esta teoria acabou por ganhar maior visibilidade com McCombs e Shaw (1972). Parece aqui existir uma clara correspondência entre a relevância dada pelos média a certos assuntos e a respetiva importância que estes mesmos assuntos acabam por ter nos indivíduos (McQuail, 2003). Por consequência, esta teoria vem dar força à ideia de que os média têm efeitos diretos no público, em particular na vinculação de memórias coletivas e no estabelecimento de uma relação entre a publicação de certos acontecimentos e a mudança de atitudes e crenças relativamente a estes (McCombs e Reynolds, 2009; Valkenburg, Peter e Walther, 2016).

Ainda assim, várias são as críticas apontadas a esta linha teórica. Uma delas é a possibilidade de o agenda-setting subestimar a realidade, no que toca à decisão do que realmente constitui a agenda pública, no sentido em que o real pode, muito provavelmente, sobrepor-se à realidade que os média publicam. Uma outra crítica é aquela que lembra que os efeitos dos média não ocorrem de forma linear, uma vez que sofrem também eles influência de vários fatores, como a ação individual, por exemplo. A discrepância entre a importância dada a um assunto por parte dos média e a importância que ele realmente adquire após entrar na agenda pública é um outro apontamento negativo. Esta crítica conduz-nos a outra: a de que existe um desfasamento entre a agenda dos média e a agenda pública, ou seja, a ideia de que os média desvalorizam temas que realmente importam ao público (Sousa, 1999).

Tentando contornar estas limitações, a teoria do agenda-building procura aprofundar os processos subjacentes à construção noticiosa. Sabemos que as escolhas dos jornalistas não são acidentais. Na sua base estão fatores determinantes como questões económicas e socioculturais, valores éticos e deontológicos, orientações e até mesmo aspetos individuais dos jornalistas como preconceitos e modos próprios de ler o mundo que os rodeia (Lopes, 2015). Torna-se, então, necessário perceber por que motivo certas temáticas e fontes são privilegiadas em relações a outras. É, pois, neste contexto que ganha valor a teoria do agenda-building. 
O objetivo central da teoria do agenda-building passa pela necessidade de descrever o processo de influência mútua entre alguns dos protagonistas do processo de construção da notícia: os meios de comunicação, os cidadãos e os representantes do poder político. Podemos ainda descrever o processo de agenda-building como "o primeiro nível do agenda-setting" (Araújo e Lopes, 2014, p. 750). De um modo simplificado, o agendabuilding diz respeito ao "processo a que as organizações noticiosas e os jornalistas recorrem para enfatizar e/ou selecionar certos eventos, questões ou fontes em detrimento de outros" (Nisbet, 2008, p. 2), pelo que se evidencia uma maior previsibilidade dos jornalistas e uma cada vez maior dependência destes relativamente às fontes que estão habituados a consultar.

\section{METODOLOGIA}

Tendo como objetivo perceber como é feita a mediatização da vacinação nos textos preventivos publicados pela imprensa generalista portuguesa, começámos por adotar uma metodologia de caráter quantitativo, criando variáveis de análise (número de fontes, identificação, geografia, tipo, estatuto e especialidade das fontes), recorrendo ao auxílio do programa de análise estatística SPSS (Statistical Package for the Social Sciences).

A amostragem resultou, portanto, de um método de seleção não probabilístico em que se elegeram os seguintes jornais: Público, Jornal de Notícias, Diário de Notícias, Correio da Manhã, Expresso e Sol, entre 1 de janeiro de 2012 e 31 de dezembro de 2014. Esta seleção teve como propósito representar toda a imprensa generalista portuguesa: desde os jornais diários aos semanários, passando por jornais de referência e populares.

Numa fase posterior, adotámos uma metodologia de natureza mais qualitativa, procurando-se aspetos específicos como repetições de conteúdos informativos em datas coincidentes e em diferentes jornais. Esta identificação foi possível através da análise ao conteúdo dos artigos, cruzando aspetos como o assunto, o tempo do acontecimento, a existência de eventos associados ao facto noticiado, entre outros. 
Esta metodologia mais qualitativa permitiu enriquecer o estudo aqui apresentado, na medida em que nos facultou informações que, além de corroborarem os dados quantitativos, permitiram perceber o como e o porquê do que é publicado sobre vacinação.

Importa ainda clarificar que a análise dos artigos foi feita do ponto de vista do leitor, uma vez que não detemos as mesmas informações que o jornalista teve quando contactou com as fontes.

\section{RESULTADOS}

Quando se fala de prevenção, os jornais portugueses valorizam prioritariamente a vacinação. Entre 2012 e 2014, este foi o tópico que mais se salientou na imprensa generalista (Público, Jornal de Notícias, Diário de Notícias, Correio da Manhã, Expresso e Sol). De um total de 439 artigos noticiosos dedicados à prevenção, 136 textos detiveram-se na vacinação. Afigura-se, pois, importante perceber quais as fontes escolhidas e quais os processos de agendamento.

\subsection{A VACINAÇÃO ATRAVÉS DA IMPRENSA GENERALISTA: A QUEM OS JORNALISTAS DÃO VOZ?}

No triénio 2012-2014, foram publicados, nos jornais Público, Jornal de Notícias, Diário de Notícias, Correio da Manhã, Expresso e Sol, 107361 artigos sobre saúde. Destes textos, apenas 439 tiveram como ângulo noticioso a prevenção e, destes, 136 trataram o tema da vacinação. Por outras palavras, se num contexto de prevenção, a vacinação se destaca com $30,1 \%$ dos textos publicados, alargando a referência ao universo dos textos de saúde publicados entre 2012 e 2014, essa temática atinge apenas 1,3\% deste total. Ainda que os números não sejam muito expressivos, revelam bastante relevância quando nos circunscrevermos ao universo da prevenção.

Comecemos por nos deter nas fontes de informação. Percorrendo todos os textos em análise, contabilizam-se 264 fontes. Quase a totalidade dos textos regista a presença de

\footnotetext{
${ }^{1}$ Dados retirados da tese de Rita Araújo (2016) intitulada «Dinâmicas de construção do noticiário de saúde: uma análise da imprensa generalista portuguesa».
} 
fontes $(94,9 \%)$ e a maior parte delas são identificadas $(93,2 \%)$. As fontes nãoidentificadas somam apenas $6,8 \%$, não havendo registo de fontes anónimas, um aspeto positivo a reter. Constata-se, pois, uma preocupação com a atribuição de uma origem e, consequentemente, uma responsabilidade relativamente às informações que tornadas públicas.

Quanto ao número de fontes, os jornalistas apresentam artigos onde se cita apenas uma fonte (36\%), seguindo-se textos com duas fontes (33,8\%). Apenas $16,2 \%$ dos textos citam três fontes, reduzindo-se essa percentagem para $8,8 \%$ quando se procuram artigos com quatro ou mais fontes. Estes valores apontam para uma representação algo empobrecida deste tópico que tanta importância tem quando se fala da prevenção da saúde. Uma grande parte dos textos nem chega a assegurar o princípio do contraditório e a pluralidade de perspetivas sobre o que se mediatiza. $O$ reduzido número de fontes pode estar relacionado com a dimensão dos textos. Os dados apontam para o domínio de artigos de dimensão breve ou média (ambos os casos somando $41,9 \%$ ) em detrimento dos textos extensos $(16,2 \%)$ onde será normal uma maior presença de fontes de informação.

Procurando conhecer a geografia das fontes, verificámos que os jornalistas tendem a falar mais com fontes nacionais do que estrangeiras e, dentro das primeiras, preferem aquelas que falam à escala do país $(64,4 \%)$, seguindo-se, com um valor bastante mais reduzido, as fontes da região norte (7,2\%). Estes valores encontram explicação, quando cruzados com a variável estatuto. De facto, há uma clara presença de fontes oficiais e especializadas institucionais que falam em nome do Governo, de uma instituição pública ou a partir do campo da saúde assumindo um carácter nacional.

Tabela 1. Geografia das fontes de informação nos textos de vacinação no triénio 20122014.

\begin{tabular}{l|c|c|c|c|c|c|c|c}
\hline \multirow{2}{*}{ Geografia das fontes } & \multicolumn{2}{|c|}{2012} & \multicolumn{2}{c|}{2013} & \multicolumn{2}{c|}{2014} & \multicolumn{2}{c}{ Total } \\
\cline { 2 - 9 } & $\mathrm{N}$ & $\%$ & $\mathrm{~N}$ & $\%$ & $\mathrm{~N}$ & $\%$ & $\mathrm{~N}$ & $\%$ \\
\hline Nacional & 58 & 63.7 & 54 & 85.7 & 58 & 52.7 & 170 & 64.4 \\
\hline Norte & 6 & 6.6 & 4 & 6.3 & 9 & 8.2 & 19 & 7.2 \\
\hline
\end{tabular}




\begin{tabular}{l|c|c|c|c|c|c|c|c}
\hline Lisboa e Vale do Tejo & 3 & 3.3 & 2 & 3.2 & 6 & 5.5 & 11 & 4.2 \\
\hline Centro & 0 & 0.0 & 0 & 0.0 & 2 & 1.8 & 2 & 0.8 \\
\hline Alentejo & 0 & 0.0 & 0 & 0.0 & 2 & 1.8 & 2 & 0.8 \\
\hline Algarve & 0 & 0.0 & 0 & 0.0 & 1 & 0.9 & 1 & 0.4 \\
\hline Ilhas & 0 & 0.0 & 0 & 0.0 & 0 & 0.0 & 0 & 0.0 \\
\hline Internacional & 5 & 5.5 & 0 & 0.0 & 8 & 7.3 & 13 & 4.9 \\
\hline Europa & 7 & 7.7 & 0 & 0.0 & 10 & 9.1 & 17 & 6.4 \\
\hline América do Norte & 1 & 1.1 & 2 & 3.2 & 10 & 9.1 & 13 & 4.9 \\
\hline África & 0 & 0.0 & 0 & 0.0 & 2 & 1.8 & 2 & 0.8 \\
\hline Ásia e Oceânia & 2 & 2.2 & 0 & 0.0 & 0 & 0.0 & 2 & 0.8 \\
\hline América Central & 0 & 0.0 & 0 & 0.0 & 0 & 0.0 & 0 & 0.0 \\
\hline América do Sul & 0 & 0.0 & 0 & 0.0 & 0 & 0.0 & 0 & 0.0 \\
\hline Não sei & 9 & 9.9 & 1 & 1.6 & 2 & 1.8 & 12 & 4.5 \\
\hline Outra & 0 & 0.0 & 0 & 0.0 & 0 & 0.0 & 0 & 0.0 \\
\hline Não se aplica & 0 & 0.0 & 0 & 0.0 & 0 & 0.0 & 0 & 0.0 \\
\hline Total & 91 & 100 & 63 & 100 & 110 & 100 & 264 & 100 \\
\hline
\end{tabular}

Fonte: Autoria própria.

Procurando saber que tipo de fontes escolhem os jornalistas, reparamos que há uma preferência por aquelas com traço humano (70,1\%). Dentro das fontes humanas, destacam-se os homens que reúnem uma percentagem de 34,1\% de citações. As fontes não-humanas somam igualmente valores que merecem atenção: $25 \%$. Trata-se aqui de fontes essencialmente documentais sobre as quais nos debruçaremos à frente.

Tabela 2. Tipo de fontes de informação nos textos de vacinação no triénio 2012-2014.

\begin{tabular}{l|l|c|c|c|c|c|c|c|c}
\hline \multirow{2}{*}{ Tipo de fonte } & \multicolumn{2}{|c|}{2012} & \multicolumn{2}{c|}{2013} & \multicolumn{2}{c|}{2014} & \multicolumn{2}{c}{ Total } \\
\cline { 3 - 11 } & & $\mathrm{N}$ & $\%$ & $\mathrm{~N}$ & $\%$ & $\mathrm{~N}$ & $\%$ & $\mathrm{~N}$ & $\%$ \\
\hline \multirow{2}{*}{ Humanas } & Masculinas & 33 & 36.3 & 19 & 30.2 & 38 & 34.5 & 90 & 34.1 \\
\cline { 2 - 10 } & Femininas & 14 & 15.4 & 13 & 20.6 & 19 & 17.3 & 46 & 17.4 \\
\cline { 2 - 10 } & Instituições & 17 & 18.7 & 11 & 17.5 & 19 & 17.3 & 47 & 17.8 \\
\cline { 2 - 10 } & Coletivas & 1 & 1.1 & 1 & 1.6 & 0 & 0.0 & 2 & 0.8 \\
\hline \multirow{2}{*}{ Não humanas } & Não pessoal & 22 & 24.2 & 16 & 25.4 & 28 & 25.5 & 66 & 25 \\
\hline \multirow{2}{*}{ Total } & Não sei & 4 & 4.4 & 3 & 4.8 & 6 & 5.5 & 13 & 4.9 \\
\hline
\end{tabular}

Fonte: Autoria própria.

RAEIC, Revista de la Asociación Española de Investigación de la Comunicación vol. 6, núm. 12 (2019), 269-288 
Quanto ao estatuto das fontes, destacam-se as fontes oficiais (governantes, diretorgeral da saúde...) que falam a partir do campo da saúde $(40,2 \%)$, seguindo-se as fontes especializadas institucionais (diretores de serviço ou de centros de investigação) também do campo da saúde (21,2\%). Falamos aqui de fontes organizadas que detêm cargos. São as elites do poder do campo da saúde que são mais interpeladas pelo discurso jornalístico.

Tabela 3. Estatuto das fontes de informação nos textos de vacinação no triénio 20122014.

\begin{tabular}{|c|c|c|c|c|c|c|c|c|c|}
\hline \multirow{7}{*}{ Campo da Saúde } & Estatuto & 2012 & 2013 & 2014 & Total & & & & \\
\hline & & $\mathrm{N}$ & $\%$ & $\mathrm{~N}$ & $\%$ & $\mathrm{~N}$ & $\%$ & $\mathrm{~N}$ & $\%$ \\
\hline & Oficial & 31 & 34.1 & 32 & 50.8 & 43 & 39.1 & 106 & 40.2 \\
\hline & Especializada Institucional & 21 & 23.1 & 10 & 15.9 & 25 & 22.7 & 56 & 21.2 \\
\hline & Documentos & 13 & 14.3 & 11 & 17.5 & 14 & 12.7 & 38 & 14.4 \\
\hline & $\begin{array}{l}\text { Especializada Não- } \\
\text { institucional }\end{array}$ & 7 & 7.8 & 1 & 1.6 & 2 & 1.8 & 10 & 3.8 \\
\hline & Media & 0 & 0.0 & 0 & 0.0 & 2 & 1.8 & 2 & 0.8 \\
\hline \multirow{8}{*}{$\begin{array}{c}\text { Fora do Campo da } \\
\text { Saúde }\end{array}$} & Media & 8 & 8.9 & 5 & 8.0 & 10 & 9.1 & 23 & 8.7 \\
\hline & Oficial & 5 & 5.5 & 3 & 4.8 & 3 & 2.7 & 11 & 4.2 \\
\hline & Especializada Institucional & 4 & 4.5 & 1 & 1.6 & 5 & 4.5 & 10 & 3.8 \\
\hline & Sociedade & 0 & 0.0 & 0 & 0.0 & 4 & 3.6 & 4 & 1.5 \\
\hline & Documentos & 1 & 1.1 & 0 & 0.0 & 2 & 1.8 & 3 & 1.1 \\
\hline & Outros & 1 & 1.1 & 0 & 0.0 & 0 & 0.0 & 1 & 0.4 \\
\hline & $\begin{array}{l}\text { Especializada Não- } \\
\text { institucional }\end{array}$ & 0 & 0.0 & 0 & 0.0 & 0 & 0.0 & 0 & 0.0 \\
\hline & Não sei & 0 & 0.0 & 0 & 0.0 & 0 & 0.0 & 0 & 0.0 \\
\hline Total & 91 & 100 & 63 & 100 & 110 & 100 & 264 & 100 & \\
\hline
\end{tabular}

Fonte: Autoria própria.

Dentro das fontes oficiais, as administrações e direções de centros de saúde são as mais ouvidas nos textos de vacinação $(25,4 \%)$, seguindo-se as especializadas institucionais que representam médicos (9,8\%). No primeiro caso, falamos de fontes como o diretorgeral da Saúde ou os administradores de hospitais, por exemplo. No caso dos médicos, referimo-nos a fontes que, além de serem especializadas neste campo, representam uma instituição ou um grupo de especialistas. Incluem-se aqui casos como os do 
bastonário da Ordem dos Médicos ou do presidente da Sociedade Portuguesa de Obstetrícia e Medicina Materno-Fetal, entre muitos outros.

Tabela 4. Estatuto pormenorizado das fontes de informação oficiais e especializadas institucionais (campo da saúde) nos textos de vacinação no triénio 2012-2014.

\begin{tabular}{|c|c|c|c|c|c|c|c|c|}
\hline \multirow[t]{2}{*}{ Estatuto } & \multicolumn{2}{|c|}{2012} & \multicolumn{2}{|c|}{2013} & \multicolumn{2}{|c|}{2014} & \multicolumn{2}{|c|}{ Total } \\
\hline & $\mathrm{N}$ & $\%$ & $\mathrm{~N}$ & $\%$ & $\mathrm{~N}$ & $\%$ & $\mathrm{~N}$ & $\%$ \\
\hline $\begin{array}{l}\text { Oficial - Administradores/diretores de centros } \\
\text { de saúde (campo da saúde) }\end{array}$ & 15 & 16.5 & 26 & 41.3 & 26 & 23.6 & 67 & 25.4 \\
\hline Oficial - Políticos (campo da saúde) & 5 & 5.5 & 4 & 6.3 & 5 & 4.5 & 14 & 5.3 \\
\hline Oficial - Outros (campo da saúde) & 11 & 12.1 & 2 & 3.2 & 12 & 10.9 & 25 & 9.5 \\
\hline $\begin{array}{l}\text { Oficial - Assessores/Porta-voz institucionais } \\
\text { (campo da saúde) }\end{array}$ & 0 & 0.0 & 0 & 0.0 & 0 & 0.0 & 0 & 0.0 \\
\hline Esp inst Médicos (campo da saúde) & 11 & 12.1 & 6 & 9.5 & 9 & 8.2 & 26 & 9.8 \\
\hline Esp inst Farmacêuticos/laboratórios (campo da saúde) & 7 & 7.7 & 4 & 6.3 & 10 & 9.1 & 21 & 8.0 \\
\hline Esp inst Outros (campo da saúde) & 2 & 2.2 & 0 & 0.0 & 4 & 3.6 & 6 & 2.3 \\
\hline Esp inst Investigadores (campo da saúde) & 1 & 1.1 & 0 & 0.0 & 2 & 1.8 & 3 & 1.1 \\
\hline Esp Inst Psicólogos (campo da saúde) & 0 & 0.0 & 0 & 0.0 & 0 & 0.0 & 0 & 0.0 \\
\hline Esp inst Enfermeiros (campo da saúde) & 0 & 0.0 & 0 & 0.0 & 0 & 0.0 & 0 & 0.0 \\
\hline Esp inst Pacientes (campo da saúde) & 0 & 0.0 & 0 & 0.0 & 0 & 0.0 & 0 & 0.0 \\
\hline Esp inst Nutricionistas (campo da saúde) & 0 & 0.0 & 0 & 0.0 & 0 & 0.0 & 0 & 0.0 \\
\hline Esp inst Bombeiros/INEM (campo da saúde) & 0 & 0.0 & 0 & 0.0 & 0 & 0.0 & 0 & 0.0 \\
\hline Esp inst Assessores (campo da saúde) & 0 & 0.0 & 0 & 0.0 & 0 & 0.0 & 0 & 0.0 \\
\hline
\end{tabular}

Fonte: Autoria própria.

De entre as fontes médicas, as especialidades mais citadas foram a Pediatria e a Pneumologia, com $38,2 \%$ e $17,6 \%$, respetivamente. O acentuado número de pediatras como fontes de informação justifica-se com o também elevado número de textos que se refere à vacinação de crianças. A título de exemplo, refiram-se os artigos sobre um novo programa de vacinação que deixa de fora a vacina Prevenar ou os artigos em que os pediatras desdramatizam a falta da vacina BCG.

\subsection{COINCIDÊNCIAS DE UM AGENDAMENTO PROVOCADO}

Pensemos agora nos processos que influenciam o agendamento das notícias. De facto, diversos são os fatores que nos permitem pensar este agendamento e que devem ser 
considerados em conjunto: o tempo do acontecimento, a existência de eventos previamente preparados que motivam a notícia, a eventual concorrência entre diferentes títulos pela mediatização dos mesmos tópicos, a proatividade de certas fontes junto de determinados jornalistas.

Como referimos anteriormente, a escolha de fontes especializadas impõe-se a fim de assegurar a credibilidade e a qualidade do que se publica. De facto, tratando-se de uma área muito específica, o jornalismo de saúde deve fazer-se com fontes que realmente dominem aquilo de que falam e que consigam ajudar a enquadrar aquilo que é notícia. Neste contexto, os jornalistas têm uma certa preferência por fontes organizadas, ou seja, dentro das fontes especializadas, preferem-se sempre aquelas que detêm cargos (diretores de serviços hospitalares, diretores de centros de investigação...). Porque apresentam maior legitimidade para representar coletivos que importa ouvir.

No caso da vacinação, estas fontes mais sofisticadas na sua organização não emergem no discurso noticioso como parte ativa no processo de agendamento mediático. Percorrendo a nossa amostra, apenas 17 dos 136 artigos se apresentam associados à realização de eventos, ou seja, $12,5 \%$. Por consequência, $87,5 \%$ dos textos parecem refletir acontecimentos aparentemente desligados de qualquer agendamento preparado em função de uma eventual cobertura mediática. Contudo, a observação mais pormenorizada dos títulos e datas das publicações sobre vacinação comprova que diferentes jornais publicam a mesma informação nos mesmos dias ou em datas próximas. Ora, esta coincidência implica uma organização de fontes que procura ser notícia através do trabalho que desenvolvem, embora esse esforço nem sempre seja muito visível nos artigos. Analisando todos os textos com vista a descobrir que agendamento eles têm subjacente, verifica-se que grande parte desse tipo de trabalho de agendamento provém da Direção-Geral da Saúde (DGS) que vai provocando uma permanente noticiabilidade através dos despachos que publica ${ }^{2}$. Assim, paralelamente

\footnotetext{
${ }^{2}$ Podem existir casos em que não seja evidente a existência de despachos como origem da informação publicada. Não podemos deixar de referir que analisamos os artigos do ponto de vista do leitor, pelo que não sabemos se a informação provem de um despacho se este não for identificado como fonte no próprio texto. Por vezes, tal pode acontecer.
} 
às fontes de traço humano, convém aqui ponderar a força das fontes documentais. $\mathrm{Na}$ verdade, elas estão bem presentes na noticiabilidade produzida em torno da vacinação e, porque falamos aqui de documentos provenientes de instituições públicas, podemos também afirmar que existe igualmente um certo controlo das fontes oficiais sobre aquilo que vai sendo noticiado.

Dos 136 artigos publicados sobre vacinação, 37 contêm documentos enquanto fontes de informação, ou seja, 27,2\% dos textos. Estes 37 artigos em que aparecem fontes documentais apresentam citações de 41 documentos, distribuídos nos três anos em estudo de forma nem sempre regular, como se pode constatar na Tabela 5.

Tabela 5. Número de casos em que as fontes são documentais no triénio 2012-2014.

\begin{tabular}{|c|c|c|}
\hline 2012 & 14 Fontes documentais & $\begin{array}{l}2 \text { Documentos oficiais } \\
9 \text { Documentos especializados } \\
2 \text { Nota/comunicado } \\
1 \text { Outros }\end{array}$ \\
\hline 2013 & 11 Fontes documentais & $\begin{array}{l}3 \text { Documentos oficiais } \\
4 \text { Documentos especializados } \\
4 \text { Notas/comunicados }\end{array}$ \\
\hline 2014 & 16 Fontes documentais & $\begin{array}{l}1 \text { Documento oficial } \\
6 \text { Documentos especializados } \\
7 \text { Notas/comunicados } \\
2 \text { Outros }\end{array}$ \\
\hline
\end{tabular}

Fonte: Autoria própria.

A possibilidade de um agendamento provocado pode também ser corroborada por uma série de coincidências de temática e de tempo relativamente ao que é noticiado nos vários jornais. Para ilustrarmos esta possibilidade, apresentamos um quadro que simplifica alguns dados e coincidências desta temática e torna a leitura da informação mais acessível. Este quadro resume o assunto, a referência temporal, a origem da informação e os jornais em que foram publicadas informações coincidentes. Ainda que seja um quadro ilustrativo, importa referir que, através dele, indicamos 16 casos em que são identificadas coincidências de temas e datas. Esses 16 exemplos são retirados de um 
total de 32 artigos noticiosos em que as fontes são documentos oficiais, especializados ou comunicados.

Tabela 6. Dados e coincidências temporais nos artigos sobre vacinação no triénio 2012-2014.

\begin{tabular}{|c|c|c|c|c|}
\hline $\begin{array}{l}\text { Origem da } \\
\text { informação }\end{array}$ & $\begin{array}{l}\text { Data da informação } \\
\text { de origem }\end{array}$ & Assunto & $\begin{array}{c}\text { Data da } \\
\text { publicação em } \\
\text { jornal }\end{array}$ & Jornal \\
\hline \multirow{2}{*}{ DGS } & \multirow{2}{*}{ Sem data } & \multirow{2}{*}{ Vacina contra a meningite } & $9 / 4 / 2012$ & $\mathrm{JN}$ \\
\hline & & & $10 / 4 / 2012$ & $\mathrm{CM}$ \\
\hline $\begin{array}{l}\text { Congresso } \\
\text { Internacional de } \\
\text { Fígado }\end{array}$ & 22 de abril de 2012 & $\begin{array}{c}\text { Grupo europeu pede mais } \\
\text { vacinas }\end{array}$ & $23 / 4 / 2012$ & $\begin{array}{l}\mathrm{CM} \\
\mathrm{JN} \\
\mathrm{DN}\end{array}$ \\
\hline \multirow{2}{*}{ DGS } & \multirow{2}{*}{ Sem data } & \multirow{2}{*}{$\begin{array}{l}\text { Vacina para a tosse convulsa em } \\
\text { adultos }\end{array}$} & $27 / 11 / 2012$ & $\mathrm{JN}$ \\
\hline & & & $28 / 11 / 2012$ & $\mathrm{CM}$ \\
\hline $\begin{array}{l}\text { Ministério da Saúde } \\
\text { DGS }\end{array}$ & $\begin{array}{l}21 \text { de setembro de } \\
2012\end{array}$ & $\begin{array}{l}\text { Vacina da gripe gratuita para } \\
\text { idosos }\end{array}$ & $22 / 9 / 2012$ & $\begin{array}{c}\text { DN } \\
\text { Público } \\
\text { JN }\end{array}$ \\
\hline \multirow{2}{*}{$\begin{array}{c}\text { Instituto Nacional } \\
\text { de Saúde Ricardo } \\
\text { Jorge }\end{array}$} & \multirow{2}{*}{ Sem data } & \multirow{2}{*}{$\begin{array}{c}\text { Estudo sobre vacinação contra } \\
\text { gripe sazonal }\end{array}$} & 29/9/2012 & $\mathrm{JN}$ \\
\hline & & & $30 / 9 / 2012$ & DN \\
\hline \multirow{2}{*}{ Vacinómetro } & \multirow{2}{*}{ Sem data } & \multirow{2}{*}{ Mais de 200 mil idosos vacinados } & $11 / 10 / 2012$ & DN \\
\hline & & & $12 / 10 / 2012$ & $\mathrm{JN}$ \\
\hline DGS & $\begin{array}{l}14 \text { de janeiro de } \\
2013\end{array}$ & Ainda há tempo para vacinação & $15 / 1 / 2013$ & $\begin{array}{l}\mathrm{CM} \\
\mathrm{JN}\end{array}$ \\
\hline DGS & Sem data & 1 milhão de vacinas & 19/9/2013 & $\begin{array}{l}\mathrm{CM} \\
\mathrm{JN}\end{array}$ \\
\hline DGS & Sem data & $\begin{array}{l}\text { DGS quer } 60 \% \text { de idosos } \\
\text { vacinados }\end{array}$ & $1 / 10 / 2013$ & $\begin{array}{c}\text { DN } \\
\text { Público }\end{array}$ \\
\hline DGS & $\begin{array}{l}14 \text { de outubro de } \\
2013\end{array}$ & $\begin{array}{c}\text { Chegada de mais de } 200 \text { mil } \\
\text { vacinas }\end{array}$ & $15 / 10 / 2013$ & $\begin{array}{l}\mathrm{DN} \\
\mathrm{JN}\end{array}$ \\
\hline Infarmed & $\begin{array}{c}8 \text { de novembro de } \\
2013\end{array}$ & Fiscalização nas farmácias & $9 / 11 / 2013$ & $\begin{array}{c}\text { DN } \\
\text { Público }\end{array}$ \\
\hline Infarmed & $\begin{array}{l}21 \text { de março de } \\
2014\end{array}$ & Vacina suspensa & $22 / 3 / 2014$ & $\begin{array}{l}\text { Público } \\
\text { DN }\end{array}$ \\
\hline $\begin{array}{l}\text { Instituto Nacional } \\
\text { de Saúde Ricardo } \\
\text { Jorge }\end{array}$ & Sem data & $50 \%$ dos idosos vacinados & $3 / 7 / 2014$ & $\begin{array}{l}\text { Público } \\
\text { JN }\end{array}$ \\
\hline DGS & Sem data & Mais vacinas da gripe & $27 / 10 / 2014$ & $\begin{array}{l}\mathrm{DN} \\
\mathrm{CM}\end{array}$ \\
\hline
\end{tabular}

RAEIC, Revista de la Asociación Española de Investigación de la Comunicación vol. 6, núm. 12 (2019), 269-288 


\begin{tabular}{l|c|c|c|c} 
DGS & $\begin{array}{c}25 \text { de novembro de } \\
2014\end{array}$ & $\begin{array}{c}\text { Recomendação da vacina contra } \\
\text { a gripe }\end{array}$ & 26/9/2014 & $\begin{array}{c}\text { JN } \\
\text { Público }\end{array}$ \\
\hline DGS & 14 de julho de 2014 & Vacina da tuberculose & $15 / 7 / 2014$ & DN \\
& \multicolumn{2}{c}{ Fonte: Autoria própria. } & & CM
\end{tabular}

O quadro permite concluir que a Direção-Geral da Saúde é aquela que mais fornece informações que são noticiadas, no dia seguinte, por vários jornais diários. Concluímos também que o Jornal de Notícias e o Diário de Notícias são aqueles que mais coincidem na publicação dos mesmos assuntos. O facto de ambos os títulos integrarem o mesmo grupo económico poderá ser uma das razões dessa coincidência, notando-se em muitos textos algumas sinergias das duas redações.

Esta situação vai de encontro à teoria do agenda-building, que discutimos no início deste artigo. Sem dúvida, mais do que serem grandes protagonistas das notícias sobre vacinação, as fontes oficiais ou especializadas institucionais (aqui representadas pela Direção-Geral da Saúde e Ministério da Saúde) são figuras ativas e influenciadoras da agenda dos meios de comunicação social em Portugal.

A análise do conteúdo dos artigos sobre vacinação - nomeadamente os dados presentes no quadro anterior - permite ainda observar que há uma doença que prevalece quando se fala da toma da vacina: a gripe. De facto, grande parte dos textos publicados sobre vacinação está também relacionada com a gripe, especialmente no incentivo à toma da vacina nos idosos. Em alguns artigos, evidencia-se uma abordagem que foca as desvantagens da toma dessa vacina, ainda que apareçam contributos de especialistas para o esclarecimento destas questões ${ }^{3}$. Este incentivo provem, essencialmente, de press releases publicados pela Direção-Geral da Saúde e divulgados pelos média.

Portanto, ainda que haja poucos eventos associados aos artigos noticiosos sobre vacinação, quando se analisa com mais pormenor o agendamento, cruzando temas,

\footnotetext{
${ }^{3}$ A título de exemplo, no dia 22 de outubro de 2014, o Jornal de Notícias publicou um artigo que se referia aos efeitos secundários negativos da vacina contra a gripe. Ainda assim, no desenvolvimento da notícia, escreveu o seguinte: «o especialista [Baltazar Nunes, do INSA] explicou à Lusa que não há qualquer descrição de uma relação causa-efeito entre a toma da vacina e o desenvolvimento da gripe».
} 
datas e jornais, verifica-se que certas fontes apresentam um forte poder para provocar noticiabilidade sobre este tópico. Há uma forte associação entre datas e assuntos coincidentes publicados em jornais distintos, assim como há uma elevada presença de fontes documentais que representam essencialmente despachos da Direção-Geral da Saúde tidos como informação relevante para publicação nos artigos.

Devemos ainda sublinhar que apenas $16,2 \%$ dos textos são extensos, o que reduz 0 espaço para se explicar convenientemente o que está em causa. Isso acontecerá porque, por um lado, as fontes produzem informação escassa ou porque os jornalistas não atribuem grande importância a esta tematização.

Neste processo de agendamento, devemos também ter em conta o tempo que medeia entre os acontecimentos e a respetiva cobertura mediática. Os dados apontam para uma escrita feita num passado recente $(35,3 \%$ dos artigos remetem para factos do dia anterior), seguindo-se um grande número de casos em que não é possível identificar uma referência temporal (30,1\%). A baixa percentagem de artigos escritos em modo de antecipação de eventos (11\%) corrobora a informação de que não há uma associação do que é noticiado a eventos específicos. Contudo, os 35,3\% de textos escritos sobre o dia anterior associam-se a artigos produzidos com informações provenientes dos despachos da véspera.

Em jeito de síntese, podemos afirmar que grande parte dos dados apontam para um agendamento noticioso sobre vacinação produzido por fontes organizadas, principalmente a Direção-Geral da Saúde, o Ministério da Saúde ou o Instituto Nacional de Saúde Doutor Ricardo Jorge. São sobretudo elas, a partir dos documentos que produzem, que promovem o agendamento deste tópico na imprensa generalista portuguesa.

\section{CONCLUSÕES}

Num contexto de produção noticiosa, a elevada mediatização das questões ligadas à vacinação tem justificação em lógicas de agendamento, nomeadamente, de agendamentos produzidos e influenciados pelas fontes organizadas. 
O papel das fontes de informação destaca-se. Prova disso foi a intensa presença de fontes nos artigos noticiosos analisados: $94,9 \%$. No entanto, este estudo salienta um fraco número de fontes por artigo, registando-se uma preferência por textos noticiosos com apenas uma fonte de informação (36\%). Em todo o caso, apresentam-se resultados positivos para o jornalismo preventivo português: das 264 fontes analisadas, 93,2\% são identificadas. Há, portanto, uma necessidade de apresentar convenientemente as fontes ouvidas. Nesta caracterização, concluiu-se também que se privilegiam fontes masculinas que falam à escala nacional. Uma das variáveis que mais interessou para este estudo foi a do estatuto da fonte. Através dela, conseguimos perceber a partir de que categoria falavam as fontes dos artigos e quais os grupos que mais interessavam aos jornalistas.

Tal como referimos na discussão da teoria do agenda-building, há uma influência recíproca entre jornalistas e fontes. Da análise dos textos sobre vacinação, compreendemos que as fontes ouvidas são imensamente repetidas: as fontes oficiais e as especializadas institucionais. Comprova-se, pois, uma dependência dos média relativamente às fontes com quem estão habituados a contactar e com quem têm canais diretos e rotineiros (por exemplo, acesso prévio a despachos e comunicados dos Ministros). Esta supremacia das fontes oficiais resulta também num processo de silenciamento de fontes que representam os membros da sociedade (por exemplo, as fontes como os pacientes ou os familiares), comprovando-se aqui a força da teoria da espiral do silêncio de Noëlle-Neumann.

Este estudo dos artigos sobre vacinação permite concluir que a escolha de determinados assuntos e fontes se explica por uma máquina de interesses que influencia diretamente todo o processo de agendamento noticioso. Os dados apontam para uma possível influência de fontes como a Direção-Geral da Saúde no agendamento mediático. Grande parte dos artigos publicados sobre vacinação tem como base despachos ou eventos realizados por entidades públicas, muitas de natureza estritamente política. Esta situação gera uma outra: muitos jornais (para não dizer quase todos) escrevem sobre os mesmos temas nos mesmos dias. 
Deste estudo podemos, então, retirar duas grandes conclusões. Por um lado, a cobertura da temática da vacinação é privilegiada pelos média, muito por influência das políticas de saúde portuguesas e das fontes que acabam por dominar os textos sobre este assunto. Por outro lado, salienta-se uma relação próxima entre os jornalistas e as fontes oficiais e especializadas institucionais, havendo há uma espécie de estrutura circular de citações, deixando-se assim em margens silenciosas outros atores. Por exemplos, os pacientes ou os cidadãos comuns.

\section{REFERÊNCIAS BIBLIOGRÁFICAS}

Araújo, R. (2016). Dinâmicas de construção do noticiário de saúde: uma análise da imprensa generalista portuguesa (Tese de Doutoramento), Universidade do Minho, Braga. Disponível em https://repositorium.sdum.uminho.pt/bitstream/1822/45761/1/Rita\%20Alexandra\%20Manso \%20Araujo.pdf.

Araújo, R. e Lopes, F. (2014). Olhando o agenda-building nos textos de saúde: um estudo dos canais e fontes de informação. Em M. Martins e J. Veríssimo (Eds.), Comunicação Global, Cultura e Tecnologia - Livro de atas do 8o Congresso Sopcom (pp. 749-753). Lisboa: SOPCOM.

Berkowitz, D. (1987). TV News Sources and News Channels: A Study in Agenda-Building. Journalism \& Mass Communication Quarterly, 64, 508-513.

Cohen, B. (1963). The press and foreign policy. Em B. Berelson e M. Janowitz (Eds.), Reader in Public Opinion and Communication. New York: The Free Press.

Corbett, J. e Mori, M. (1999). Medicine, media and celebrities: news coverage of the breast cancer, 1960-1995. Journal of Mass Communication Quarterly, 76(2), 229-249.

Decreto-lei no 5786/2015, de 1 de Junho, Ministério da Saúde.

Friedman, D., Tanner, A. e Rose, I. (2014). Health journalists' perceptions of their communities and implications for the delivery of health information in the news. Journal of community health, 39, 378-385.

Gomes, E. (2012). Jornalismo de Saúde: Prevenir ou Remediar? Análise dos textos de saúde dos jornais: Público, Jornal de Notícias e Expresso de 2011 (Dissertação de Mestrado), Universidade do Minho, Braga. Disponível em https://repositorium.sdum.uminho.pt/bitstream/1822/20684/ 1/Emiliana\%20Sofia\%20Coelho\%20Gomes.pdf. 
Gutiérrez, I. e Jiménez, A. (2001). Documentación para el periodismo especializado. Revista General de Información y Documentación, 11, 33-60.

Hinnant, A. e Len-Ríos, M. (2009). Tacit understandings of health literacy: interview and survey research with health journalists. Science Communication, 31, 84-115. Disponível em http://journals.sagepub.com/doi/abs/10.1177/1075547009335345.

Hodgetts, D., Chamberlain, K., Scammell, M., Karapu, R. e Nikora, L. (2008). Constructing Health News: Possibilities for a Civic-Oriented Journalism. Health, 12, 43-66. Disponível em http://journals.sagepub.com/doi/abs/10.1177/1363459307083697.

Lippman, W. (1922). Public Opinion. New York: Harcourt Brace Jovanovitch.

Lopes, F. (2015). Jornalista. Profissão ameaçada. Lisboa: Alêtheia Editores.

Lopes, F., Ruão, T., Marinho, S. e Araújo, R. (2012). A saúde em notícia entre 2008 e 2010: retratos do que a imprensa portuguesa mostrou. Revista Comunicação e Sociedade, 129-170. Disponível em http://revistacomsoc.pt/index.php/comsoc/article/view/1361.

McCombs, M. e Reynolds, A. (2009). How the news shapes our civic agenda. Em M. Bryant (Ed.), Media effects: Advances in theory and research (pp. 1-16). New York: Routledge.

McCombs, M. e Shaw, D. (1972). The agenda setting function of mass media. Public Opinion Quarterly, 36, 176-187.

McQuail, D. (2003). Teoria da Comunicação de Massas. Lisboa: Fundação Calouste Gulbenkian. Muñoz- Torres, J. (1997). Aproximación al concepto de Información Periodística Especializada. Em F. Ramírez (Ed.), Estudios sobre información periodística especializada (pp. 25-41). Valencia: Fundación Universitaria San Pablo.

Noëlle-Neumann, E. (2000). Public Perception Theory: The Concept of Spiral of Silence. Selected by Chang Changfu. Science of Public Media: Influence Research Mode. Beijing: China Social Science Press.

Noëlle-Neumann, E. (1995). La espiral del silencio. Una teoría de la opinión pública. Em J. Ferry, M. Wolton e D. Ferry (Eds.), El nuevo espacio público. Barcelona: Gedisa Editorial.

Nisbet, M. (2008). Agenda Building. Em W. Donsbach (Ed.), International Encyclopedia of Communication. New York: Blackwell Publishing. 
Silveira, P. e Marôpo, L. (2014). Jornalismo e Construção Social da Realidade: Um contributo para o debate teórico. Revista Comunicando, 3, 7-19. Disponível em http://www.revistacomunicando.sopcom.pt/ficheiros/20141219-0 2.pdf.

Sousa, J. (1999). As notícias e os seus efeitos. As "teorias do jornalismo e dos efeitos sociais dos media jornalísticos. Porto: Universidade Fernando Pessoa.

Valkenburg, P. e Walther, J. (2016). Media effects: theory and research. Annual Review of Psychology, 67, 315-338. 